\title{
EL DIÁLOGO PLATÓNICO ENTRE LA LITERATURA Y LA FILOSOFÍA
}

\author{
Dr. (C) Lucas Díaz López*
}

En el presente artículo se intenta mostrar la situación liminar de la obra platónica respecto a la distinción entre literatura y filosofía. Para ello, a partir de un pasaje del Fedón en el que es nombrado el autor del diálogo, se analiza la complejidad de niveles y dimensiones que presenta el formato literario de los diálogos y la necesidad hermenéutica que le acompaña.

Palabras clave: diálogo, drama, Fedón, hermenéutica, literatura.

THE PLATONIC DIALOGUE BETWEEN LITERATURE AND PHILOSOPHY

This article attempts to show the border situation of Plato's work in connection with the distinction between literature and philosophy. To do this, we analyze, in a specific passage of the Phaedo, the complexity of levels and dimensions and the hermeneutical need that the literary form of the dialogue presents.

Keywords: dialogue, drama, Phaedo, hermeneutics, literature.

*Universidad Complutense de Madrid, Madrid, España. Correo electrónico: diazlopezlucas@gmail.com 
SI ALGUNA OBRA PUEDE INTRODUCIR DUDAS Y HACERNOS REFLEXIONAR ACERCA de las fronteras entre la literatura y la filosofía, esa es sin duda la obra de Platón. El marcado carácter narrativo de los diálogos está fuera de discusión. Frente a las convenciones del posterior género del diálogo filosófico, los diálogos platónicos, para decirlo con Hegel, "no están compuestos como coloquios formados, en realidad, por varios monólogos en que el uno sostenga una cosa y el otro otra, aferrándose cada cual a sus opiniones”'. El diálogo platónico se caracteriza por una vocación realista que se plasma en un interés en situar tanto espacio como temporalmente la conversación, en la complejidad de los personajes, en hacer fluir la conversación allí a donde vaya. Hay aquí algo más que un coqueteo con lo narrativo, que sitúa los diálogos de Platón en una posición bastante difusa respecto de la oposición literatura-filosofía. En este artículo esbozaremos las líneas generales de lo que sería un acercamiento a la obra platónica teniendo en cuenta este carácter liminar de los diálogos ${ }^{2}$. Este tipo de lectura se hace más imperativa si atendemos a las condiciones específicas de aparición de los textos platónicos, ajenas a la distinción mencionada.

2.

En un determinado momento del Fedón se mantiene la siguiente conversación entre los personajes del primer nivel dramático, Equécrates y el propio Fedón:

EQUE.-¿Quiénes fueron, Fedón, los alli presentes?

FED.-De los de la tierra, estuvo este Apolodoro [del que se acaba de hablar], y Critóbulo y su padre, y además Hermógenes, Epigenes, Esquines y Antistenes. Y también estaban Ctesipo el peanio, y Menéxeno, y algunos otros más de su tierra. Platón estaba enfermo, creo. EQUE.-¿Y hubo algunos extranjeros?

FED.-Si: Simmias el tebano, y Cebes y Fedondes, y de Mégara, Euclides

1 Hegel, G. W. F, Lecciones sobre Historia de la Filosofia, FCE, México, 1981, p. 144.

2 Por supuesto, no somos pioneros en este intento. Ya desde Schleiermacher la hermenéutica platónica ha buscado una explicación holística que dé cuenta de la presencia de aspectos narrativos y dramáticos en los diálogos. Cfr., como muestra de este interés, los libros publicados hace ya unos años de Press, G. A. (ED.), Plato's dialogues. New Studies and Interpretations, Rowman \& Littlefield, Maryland, 1993, o GonzALEZ, F. J. (ED.), The Third Way. New Directions in Platonic Studies, Rowman \& Littlefield, Maryland, 1995. La denominada escuela de Tubinga-Milán también centra su "nueva lectura" en una atención a los detalles dramático-escénicos, aunque lo hace de acuerdo a un proyecto de reconstrucción más o menos tradicional de las doctrinas no escritas platónicas. 


\section{y Terpsión.}

EQUE.-¿Y qué? ¿Asistieron Aristipo y Cleómbroto?

FED.-Pues no, ya que estaban, se decía, en Egina.

EQUE.-¿Algún otro estuvo?

FED.-Estos fueron, más o menos, los que asistieron ${ }^{3}$.

Con frecuencia se ha subrayado la mención que en este texto se hace de Platón que, como autor y responsable último de lo que en el texto se dice, produce una indudable descarga de responsabilidad enunciativa, recayendo ésta en Fedón, quien, no obstante, es un personaje del propio texto ${ }^{4}$. Esta paradoja es innegable, pero es preciso analizarla más en detalle. Sucede, en efecto, que en el nivel inmediato de la conversación, el ficcional, este catálogo presenta una serie de menciones que no implican una explícita ruptura del marco dramático. Es verdad que el texto establece una distinción entre los asistentes, la de ser conciudadanos de Sócrates o extranjeros, pero, por más relevante que sea de un modo interno al texto, tal distinción no lo rebasa. Cada uno de los mencionados se encuentra en el mismo plano que los personajes del diálogo primario. La enumeración de nombres es, pues, vista desde este nivel, sustancialmente uniforme. Sin duda, la presencia o no de álguien puede ser relevante en función de múltiples circunstancias. Por los motivos que sea, a cada cual podría suscitarle cierta reacción la mención de uno de los asistentes, así como la ausencia de otro, pero cada uno de esos asistentes pertenece al mismo mundo, a aquel en el que se encuentran Fedón y Equécrates; desde esta perspectiva, ninguna mención produce, pues, una ruptura de marco, una incoherencia de nivel. La división, sin duda nada trivial, en $x e$ noi o politai ya ha asumido este inicial horizonte nivelador. El catálogo en el nivel ficcional es una lista de menciones que en cierto respecto pueden considerarse homogéneas.

Sin embargo, pese a que se puede seguir contemplando esa perspectiva, un momento de ese catálogo produce la emergencia del nivel en el que se encuentran ya no los personajes, sino el autor y el lector, el nivel literario. Un lector tiene al menos una información sobre los personajes del mundo del diálogo que ellos no tienen, esto es, la de que son personajes, la de que son parte de un escrito de Platón. El lector tiene un punto de vista, digamos, externo a la acción que se presenta inmediatamente. En otras palabras, el lector tiene la referencia autorial. De ahí que, desde este punto de vista, la mención del nombre de Platón en el catálogo tenga ciertos efectos que rebasan el ámbito de los personajes. Esa mención podría suscitar diversas reacciones en el plano de los personajes, pero no del mismo calado que la que produce al lector. Hay aquí un punto a tener en cuenta.

Para el punto de vista de Equécrates, la mención de Platón se inserta en el apartado asistentes atenienses, e informa de las dudas de Fedón ante la presencia de uno de los que solian frecuentar la compañía de Sócrates. Este trato habitual hace que la mención,

3 Platón, Fedón, 59 b-c.

4 Cfr. ClaY, D., "Plato's First Words", Yale Classical Studies 29, 1992, p. 120; JoHnson, W. A., "Dramatic frame and philosophic idea in Plato", The American Journal of Philology, 119:4, 1998, pp. 578-581. 
la única, por lo demás, que se formula dubitativamente, no sea relevante: es normal que se inforine de las dudas, si se tienen, sobre la presencia de alguien de quien esperariamos que estuviera presente. Pero, en todo caso, tampoco pasaría nada extremadamente importante si la mención de Platón por parte de Fedón estuviese marcada, por ejemplo, de un modo irónico, como si fuera un reproche, etc. Aun así, para Equécrates, ello no supondría más que un especial énfasis en uno de los personajes de ese mundo, nunca una mención del autor. De hecho, como puede apreciarse en el texto, Equécrates pasa por encima de esa mención, preguntando inmediatamente por la presencia de algún extranjero. Además, durante el relato, no se vuelve a nombrar a Platón, ni parece echársele de menos, de modo que la mención resulta en este nivel meramente anecdótica. En el plano de los personajes, por lo tanto, no se produce ruptura de marco; la mención de Platón sólo nos afecta desde el momento en que somos lectores.

La señal de autor nos devuelve, por tanto, a nuestra perspectiva de lectores; con ello no perdemos el punto de vista de los personajes, simplemente lo reconocemos como diferente del nuestro. La comprensión del lector-espectador no se desentiende, ni mucho menos, del punto de vista que atiende al flujo comunicacional entre los personajes, antes bien, requiere de ese punto de vista, sin el cual no habría mensaje. Es más bien la repercusión de ese flujo comunicacional lo que se va alterando: el lector, como instancia totalizadora, relaciona todos los momentos de la obra dramática, enlazándolos en busca de un sentido; a cada paso procede anticipando ese sentido global de la obra, confirmándolo o reelaborándolo en función del desarrollo de la acción ficcional.

Analicemos el distinto modo de enfocar el texto platónico si nos ponemos en la perspectiva de uno de los personajes o si nos situamos ante él como lectores. Desde el punto de vista de la acción, debe asumirse la contingencia de los sucesos, así como la novedad de lo narrado. Siempre cuenta Fedón por primera vez la última conversación de Sócrates. Este relato analéptico, sin embargo, se nos aparece de otro modo si lo afrontamos como lectores: ahora, las palabras de Fedón han sido calculadas y dispuestas por Platón, de modo que lo narrado, el hecho de que esté narrado, el a quién esté narrado, el dónde está narrado, etc., se nos muestran como una totalidad cerrada, cuyas partes remiten unas a otras y nos exigen darles un sentido. La unidad autorial que ponemos de este modo a la base de nuestra recepción es un movimiento de totalización de los elementos de la obra, más allá de lo que pueda entenderse por su desnuda literalidad. Debemos ahora entender las estrategias pragmáticas de los personajes, sus deslizamientos argumentativos, sus conductas puntuales, etc., como estrategias literarias del autor destinadas a la producción de sentido.

Pero la producción de totalizaciones por parte del lector es parte del proceso de la comprensión; la especificidad de este texto radica en el efecto irónico que genera ${ }^{5}$. Las

5 Sobre la comprensión como "anticipación de perfección" es obligado remitir a GADAMER, H.-G., Verdad y Método I, Sígueme, Salamanca, 2005, pp. 360-363. Sobre la ironía como figura de "distancia enunciativa", $c f r$. Lozano, J., Peña-Marín, C. \& ABril, G., Análisis del discurso, Cátedra, Madrid, 1982, pp. 159-164. 
palabras de Fedón son triviales en el nivel ficcional, pero completamente relevantes respecto del nivel literario del texto. Las discrepancias informativas suelen generar efectos irónicos; así por ejemplo las distintas alusiones que se realizan en otros diálogos sobre la trágica suerte de Sócrates muestran, a modo de una sombra funesta, el perfil de un camino que culmina en la cicuta; pero esas anticipaciones son sólo tales desde nuestro punto de vista; en el nivel ficcional, son simples amenazas ${ }^{6}$. La ironía se juega en esa diferencia entre niveles. Sin embargo, aquí el efecto irónico es especial, pues la discrepancia informativa señala hacia un dato que, como tal, nos caracteriza como lectores: el conocimiento de que los personajes del diálogo son personajes de un diálogo escrito por Platón. No se trata de que nosotros sepamos un dato más que los personajes, sino de que sabemos algo que los propios personajes, en virtud del realismo que impregna la obra platónica, no pueden en ningún caso saber. En efecto, ninguno de los asistentes a la conversación, empezando por Equécrates, alcanza nuestro punto de vista: ellos se hallan condenados a su perspectiva interna al diálogo, desde la que no saben que son personajes. Somos nosotros quienes sabemos que ese diálogo y esa narración son parte de una obra escrita por Platón. Luego, la mención del nombre del autor es una activación, para nosotros, de nuestra conciencia de lectores, contrapuesta a la inconsciencia de los personajes. La mención del autor nos pone de frente a nuestra exterioridad al mundo del diálogo. El nombre "Platón" produce nuestra autoconsciencia, pone de manifiesto la diferencia que media entre nosotros y ellos. De este modo, supone una importancia crítica para la percepción hermenéutica del relato.

3.

Quizá no por casualidad, el diálogo del que nos hemos ocupado lidia con una noción que ha sufrido un desvío semántico importante; se trata del alma ( $p s y k h e ́)$. En el diálogo se insiste en ver en ella precisamente una función totalizadora de la discontinuidad y yuxtaposición que se nombra como cuerpo (sôma $)^{7}$. La escatología final se encarga de mostrar esto, caracterizando al alma como una única decisión que se toma en función de cómo se ha obrado en vida. Esta decisión final es la expresión mítica de una perspectiva global sobre el entero curso de la vida ${ }^{8}$.

El alma, como aquello que va al Hades, cumple las funciones de totalización que el límite de la muerte suministra. Impone un sentido al conjunto: de ahí que durante el diálogo se nos insista en la necesidad práctica de conducirse en referencia a ese elemento y no al cuerpo ${ }^{9}$. No se trata de una opción por una suerte de vida contemplativa, sino de una insistencia en el punto de vista que asigna a cada cosa su sitio y no se deja conducir por el ahora

6 Cfr. Platón, Menón, 94 e, Gorgias, 486 a-b.

7 Cfr. Platón, Fedón, 64 a y ss.

8 Sobre el "mito de Er" en La República, cfr. Martínez MarzoA, F., Ser y diálogo. Leer a Platón, Istmo, Madrid, 1996.

9 Cfr. la revisión de las aretai que se realiza en Fedón 68 a y ss. Sobre la referencia a la muerte como un principio de cierre para la "existencia humana" y sobre la relevancia de esa referencia a la hora de pensar una asunción “auténtica" de tal existencia, cfr. Heidegger, M., Sein und Zeit, Max Niemeyer, Tubinga, 2006, §46 y ss. 
y ahora y ahora... Ese es el punto de vista que hace comparecer a la cosa tal y como es, y por eso el alma es divina. La referencia a la divinidad supone, en el pensamiento griego, desde Homero en adelante, instalarse en un punto de vista que trasciende la particularidad de la acción (una plaga en el campamento aqueo, la captura de un determinado rehén) para atender a una conexión de los acontecimientos que muestra su relevancia respecto de la trama en que se insertan (castigo de Apolo) ${ }^{10}$. Con el pitagorismo y las denominadas sectas órficas, la psykhé acabará asumiendo de un modo explícito ese papel totalizador y con ello la caracterización de divina. Entonces es cuando el alma comienza a protagonizar toda una serie de relatos escatológicos que tienen como función expresar la peculiaridad del punto de vista que la toma como referencia. Durante el helenismo, las exigencias espirituales de la época pondrán el acento en estos relatos míticos, insertándolos en un horizonte de comprensión ajeno al de su surgimiento. El Fedón, con su insistencia totalizadora, señala el lugar específico en el que estos relatos se insertan dentro del pensamiento griego.

La pragmática del texto platónico recoge estos elementos, situándolos en un nivel de comprensión preciso: la presentación, por medio del relato de Fedón, de esa figura unitaria que es el alma de Sócrates. El diálogo versa así no sólo sobre el alma, como parece desprenderse de la conversación entendida a partir del nivel ficcional, sino también sobre la vida de Sócrates, esto es, sobre lo que Sócrates es o ha sido, sobre lo que Sócrates ha hecho o hace. Nos encontramos así ante un diálogo autorreferencial, un diálogo que habla del diálogo, esto es, de lo que Sócrates hace. Esto adquiere su confirmación desde el momento en que el propio Sócrates expone en el diálogo su autobiografía intelectual (96 a y ss.), que es, desde luego, un discurso metodológico de la dialéctica. En este tramo, que precede al larguísimo discurso escatológico del final, el género literario del diálogo se vuelca sobre sí mismo, reflexionando sobre la figura socrática que suele protagonizarlo y contraponiendo sus acciones al género precedente conocido como la peri phýseos historía. La necesidad de adoptar la perspectiva del eîdos, el examen y refutación de hypothéseis en función de las características relacionales eidéticas, son aspectos que se repiten, en efecto, a lo largo de todos los diálogos, aunque pueden verse de un modo más cristalino en obras de complejidad menor como la mayoría de los llamados diálogos miméticos. La psyché, en cuanto designa la constitución de una totalidad vital, es el motivo que moviliza una suerte de autorreflexión dialógica sólo perceptible desde el nivel literario de consideración del diálogo.

\section{4.}

Unas palabras más sobre la psykhé. En el Fedro, la psykhé va a pasar a designar en determinado momento la función autorial, que vivifica el texto, proporcionado un fondo intencional que le hace "capaz de defenderse". La dimensión autorial que se pliega sobre el escrito constituye un lógos "vivo y con alma" (zônta kai émpsykhon, 276 a), es decir, articulado ( $c f r$. sobre zôon, $264 \mathrm{c}$ ) y con un exceso (o una carencia) de sentido que exige

10 Cfr. НOMERo, lliada I, 93-100. 
la labor interpretativa del lector. Según esto, todo texto contiene un exceso tal, una cierta negatividad que impide su reducción a univocidades semánticas. De ahí que las letras respondan "con el más altivo de los silencios" ( 275 d); cualquier acto de comprensión, también a nivel oral, excede el nivel de la mera recepción pasiva, implicando al receptor en el proceso mismo de la comprensión. En este sentido, la pasividad en la comprensión no es tanto una presunta recepción neutra de un mensaje claro en sí mismo cuanto una tácita aceptación de los esquemas comprensivos predominantes. El carácter hipomnemático de la escritura apunta a este carácter eminentemente activo de la lectura, que busca constituir a través de los signos mudos un sentido organizado y cabal $^{11}$. La psyché de la obra es, pues, su interpretación, en cuanto totalización y conexión reciproca de los enunciados, al igual que la psyché del sôma es la pluralidad de sucesos aparentemente yuxtapuestos en cuanto comprendidos como figura unitaria.

Si todo texto reenvía a la unidad autorial que le subyace, en el caso de la mímesis pura que son los diálogos platónicos este reenvío es exigido al lector sin proporcionarle más punto de apoyo que las palabras mimetizadas de los personajes. Así, señala Sócrates en La República, que en la mímesis, "cuando se suprimen los relatos que intercala el poeta entre los discursos y se dejan sólo los diálogos" (III, 394 b), las palabras son presentadas "como si fuera otro el que habla" (393 c). Pero, "si el poeta nunca se escondiese, toda su poesía y su narración serían producidas sin imitación alguna" (393c-d). El poeta, el autor, se esconde cuando hay mimesis. La unidad autorial se dispersa, sin permitir destacar de un modo inmediato unos tramos de texto sobre otros. El autor de los diálogos es un autor ausente, un autor que se busca en la unidad del ácto de la comprensión. En este sentido los diálogos escenifican esa exigencia de auxilio que todo texto contiene. Si bien en su nivel ficcional las palabras proferidas por uno $u$ otro personaje tienen su soporte en la presencia del enunciador, que es capaz de aclarar los malentendidos y de explicar los pasos argumentativos, en el nivel literario, sin embargo, nos encontramos con ese silencio de las letras del Fedro en su forma más cruda.

\section{5.}

Las dimensiones hermenéuticas del texto platónico pueden parecer enormes, desde luego, si se lo compara con la prosa académica, pero no son nada extravagantes si se lo aproxima a cualquier obra dramática. Los resultados obtenidos por las investigaciones sobre la semiótica de las obras teatrales confirman, en efecto, los análisis precedentes y permiten profundizar en ellos. Frente al carácter estrictamente narrativo de la novela, el drama es, en su estructura representacional, autárquico, es decir, presenta la acción de un modo inmediato a través de sus personajes, sin intervenciones extraescénicas ${ }^{12}$. Este es

11 Sobre la relación entre la comprensión hermenéutica y el Fedro platónico, cfr. las obras de LLEDÓ, E., El silencio de la escritura, Austral, Madrid, 1991, y El surco del tiempo, Crítica, Barcelona, 1992.

12 Cfr. Bobes Naves, M. C., Semiología de la obra dramática, Taurus, Madrid, 1987, p. 65; Spang, K., Teoría del drama: lectura y análisis de un obra teatral, Eunsa, Pamplona, 1991, pp. 28-29. Todo ello sin perjuicio 
un primer nivel semiótico del texto dramático, lo que hemos llamado el nivel del relato o de los personajes; la comunicación se realiza en este nivel por medio de emisores y receptores internos al texto y en coherencia con él. Ahora bien, este nivel ficcional se inserta dentro de un proceso comunicativo más amplio, que lo incluye a la vez que lo rebasa: el nivel en el que se encuentran el autor y el lector-espectador o nivel literario.

El proceso comunicativo del drama se muestra aquí en toda su complejidad: el Autor se comunica con el Espectador por medio de un Texto que se compone de procesos comunicativos entre Personajes. Podemos formalizar este proceso así:

$$
\mathrm{A} \rightarrow \mathrm{T}\{\mathrm{P} 1 \leftrightarrow \mathrm{P} 2 \leftrightarrow \mathrm{P} 3 \ldots\} \rightarrow \mathrm{E} ;
$$

donde "A" es el autor, "E" el espectador, " $T$ " el texto y "P1", "P2", etc. los distintos personajes. Las flechas tratan de reflejar la dirección de los procesos comunicativos: la bidireccionalidad del diálogo dramático y la unidireccionalidad de la comunicación literaria ${ }^{13}$. Los corchetes indican un salto de nivel, de la realidad a la ficción, por así decir.

Valga el esquema para ofrecer una idea del proceso comunicativo del drama, pero téngase en cuenta que es una abstracción: la comprensión de la obra parte del nivel ficcional, de modo que lo que va entre corchetes es el nivel primario o inmediato, sobre el que el nivel literario opera de un modo englobante. La comprensión es el trabajo intelectual que realiza el Receptor reconstruyendo hermenéuticamente la intención del Autor plasmada en el texto. La unidad del Autor supone, pues, un polo orientativo de la comprensión; en ningún caso una referencia objetiva contrastable con los resultados del acto comprensivo. Cada recepción construye así la intención autorial a partir del mensaje fijado en el texto, generando una suerte de sentido global de la obra.

De esta suerte, el Receptor del Texto realiza una totalización con los distintos enunciados de los Personajes, generando un mensaje comunicacional que asigna al Autor. Se producen así dos actos comprensivos simultáneos: por un lado, las interacciones de los Personajes son vistas a la luz del desarrollo de la historia, insertas en la trama intraescénica -este es el nivel inmediato o ficcional-; por otro, esas mismas interacciones son

de las controladas metalepsis o rupturas de marco que puedan llevarse a cabo, haciendo intervenir al público o haciendo referencias a algún otro elemento de la realidad no-escénica. Estas metalepsis, más propias del teatro moderno o contemporáneo, pero que ya hallan antecedentes en determinados momentos de la obra de Aristófanes, en cuanto que se entienden como transgresiones de la norma de la autarquía confirman su validez general, del mismo modo que el mentiroso kantiano supone en su conducta la norma de la sinceridad comunicacional.

13 Tal unidireccionalidad no implica, desde luego, que la relación Autor-Espectador sea completamente lineal: el proceso creativo tiene siempre en cuenta, a la manera de una anticipación, el proceso de recepción. El Autor, además, es una categoría que no se agota en el análisis de un Texto; la intertextualidad produce una distancia interna en esa categoría entre el "autor implícito", textualizado en la obra, y el "autor real", al que han de remitirse los distintos "autores implícitos" de sus obras. En cualquier caso, súplanse las carencias del apresurado esquema dada la intención del artículo. Para un análisis más complejo del proceso de recepción, me remito a las obras ya citadas de Bobes Naves y de Spang. 
puestas en conexión con el contexto general de la obra (incluso de otras obras del mismo autor), generando así un nivel literario de comprensión en donde los momentos relativamente dispersos se remiten al desenvolvimiento de una trama argumental unitaria. Los enunciados dramáticos, llamémosles así, tienen sentidos distintos en función del nivel en el que se los encuadre, sea que se los entienda dentro del nivel ficcional, sea que se los encuadre dentro del mensaje del Autor. Como puede apreciarse, los análisis anteriores del Fedón sirven como ejemplo de la presencia de esta duplicidad de niveles de comprensión del texto dramático en los diálogos platónicos y esperan hacer entender la aportación que supondría tener en cuenta de un modo explícito esta duplicidad a la hora de interpretar la obra de Platón.

6.

Así pues, los textos platónicos tienen unas características formales determinadas que todo acercamiento hermenéutico riguroso debería tener en cuenta, de un modo preliminar, para delinear sus estrategias interpretativas generales. Los diálogos platónicos son textos dramáticos puros, con una estricta vocación realista que no rompe internamente el marco representativo, aun cuando se puedan detectar ciertas alusiones que remiten al lector, no así a los personajes, a acontecimientos aún por venir (por ejemplo, las anticipaciones de la trágica suerte de Sócrates) o, incluso, al autor del texto $\mathrm{mismo}^{14}$. En cualquier caso, intraescénicamente, en el nivel ficcional, el marco se mantiene y los personajes se conducen con una marcada intención mimética que contrasta con las posteriores obras del género diálogo filosófico, donde los personajes abandonan la concreción y tienden a representar las posiciones filosóficas que se quiere confrontar. Este realismo del drama platónico, acentuado por la historicidad de sus figuras, se impone también en la marcha de la conversación, que se ve desviada por consideraciones colaterales, por excursos, llegando al extremo del Fedro en donde la exuberancia escénica es tal que invade el diálogo, haciendo que se converse sobre temas que surgen a raíz de los elementos que la componen ${ }^{15}$. Todo ello produce una ausencia de guías generales, de indicaciones autoriales, sobre cómo entender el sentido del texto en general, desde la intención que lo anima hasta las conclusiones que presenta, pasando por la veracidad e incluso la seriedad de sus desarrollos ${ }^{16}$. Esta carencia de asideros hermenéuticos impone un acercamiento cauteloso al texto que esté atento a cualquier tipo de indicación que, de las palabras de los personajes, permita extraer

14 Sobre las anticipaciones de la muerte de Sócrates, cfr. CLAY, D., Platonic questions. Dialogues with the Silent Philosopher, The Pennsilvania State UP, Pennsilvania, 2000, pp. 35 y ss. Sobre rupturas de marco y metalepsis, cfr. Garcia Landa, J. A., Acción, relato, discurso. Estructura de la ficción literaria, Ediciones Universidad de Salamanca, Salamanca, 1998, p. 307.

15 Cfr. Diaz LóPEz, L., "El Fedro y su escena", Kinesis, 09 (Edição Especial), Julho 2013, pp. 87-98.

16 Cfr. Halliwell, S., "The Theory and the Practice of the Narrative in Plato" en Grethlein, Rengakos (ED.), Narratology and Interpretation. The content of narrative form in ancient literature, Walter de Gruyter, BerlinNueva York, 2009, p. 22. El amplio espectro de las interpretaciones que se han dado del Parménides es un magnifico ejemplo de esta desorientación hermenéutica: de él se ha dicho tanto que es una exposición global de todas las posibles posiciones ontológicas como que es una mera práctica lógico-argumentativa o incluso una gran broma. 
pautas para la comprensión global del diálogo. En este sentido, una lectura rigurosa de un diálogo de Platón debe dar cuenta del mayor número de elementos presentes en el texto y, para ello, debe tener en consideración las tres dimensiones que vertebran ese texto.

En primer lugar, no debe atender exclusivamente, como parece desprenderse del tratamiento de ciertos tramos textuales en algunos artículos, a lo que se podría llamar la sintaxis del texto, esto es, a su coherencia e interconexiones lógicas. El análisis lógicoformal de los argumentos tiene una indudable utilidad y puede llegar a ser esclarecedor con respecto a algunos pasajes de la obra platónica, pero no debe comprenderse como un recurso autonomizable del resto de dimensiones hermenéuticas, puesto que ni siquiera como tramo textual es un momento del texto independiente del anterior y del siguiente. $\mathrm{La}$ totalización que el lector realiza a cada paso de la obra impide considerar la forma lógica de un argumento con independencia de su función en el decurso global de la conversación que se presenta en el texto. De hecho, esto ni siquiera ocurre en el caso de artículos que se dedican a formalizar pasajes de algún diálogo, puesto que a su base pueden descubrirse ciertas decisiones sobre la importancia del pasaje en función de su situación en la obra o de los interlocutores implicados. En cualquier caso, el entendimiento correcto de los pasos argumentativos, el esqueleto lógico-formal, es, sí, una pieza necesaria para la comprensión del texto, pero no culmina ese proceso, y su autonomización, su tratamiento aislado, más bien, desatiende una serie de aspectos irrenunciables a la hora de habérselas con la carne de esos argumentos.

En segundo lugar, tampoco debería dedicarse solamente a recoger el contenido de las distintas doctrinas u opiniones que el texto vaya presentando, a la manera de la tradicional doxografía. Esta dimensión semántica del texto es, obviamente, otro aspecto necesario para la comprensión, puesto que el correcto entendimiento de las tesis que se van sosteniendo en el texto es de nuevo una pieza necesaria para el seguimiento de los argumentos, pero el tratamiento aislado de esos contenidos, de nuevo, realiza cortes que de algún modo son artificiales en el organismo dialógico que se está analizando. La autonomización de ciertos tramos textuales en la forma de teorías de " $\mathrm{X}$ " (por ejemplo, de Protágoras, de Sócrates o incluso de Platón) no tiene en cuenta el flujo dialógico en el que esos tramos se hallan inmersos, que condiciona contextualmente la aparición de esas opiniones, que pueden ser sostenidas momentáneamente en función de las necesidades argumentativas de la conversación, así como pueden tener su razón de ser en determinados momentos anteriores de la discusión, que les condiciona ineludiblemente. La consideración aislada de este aspecto semántico, pues, hace abstracción de un marco dialógico en donde esos contenidos se presentan, que influye decisivamente en su aparición e incluso en su sostenimiento ${ }^{17 .}$

17 No quiero sostener aqui que las doctrinas que aparecen en los diálogos platónicos no correspondan con las doctrinas que sostuvieron los personajes históricos a los que se les atribuye. No entro en esta cuestión, simplemente quiero resaltar la necesidad de contextualizar esas doctrinas a la hora de realizar una interpretación del diálogo en el que aparecen. 
La lectura de un diálogo platónico debe intentar no caer en estos análisis unilaterales o, al menos, debe intentar situarlos respecto de la totalidad en la que se incluyen. Esta totalidad se cumple en lo que llamaremos la dimensión pragmática del texto platónico. El diálogo moviliza siempre una escena espacio-temporal y unos personajes; las conversaciones, aunque frecuentemente presenten un carácter relativamente abstracto respecto de la situación concreta, sin embargo, no olvidan esa situación escénico-prosopográfića y ocurren partiendo de ella, argumentando desde ella y cerrándose en virtud de ella ${ }^{18}$. La dimensión pragmática, por tanto, abarca tanto los aspectos lógico-argumentativos como los semántico-doctrinales, pero los conjuga con una situación concreta que les proporciona un sentido global del que carecen si se consideran aisladamente. Este exceso, el sentido, que no se reduce ni a la logicidad de la conversación ni al contenido de la misma, es el núcleo de comprensión que ilumina desde sí el entendimiento de determinados pasajes, su conexión con lo anteriormente dicho y su relación con lo que se dirá. La situación dialógica, pues, es un factor englobante que exige una lectura compleja del diálogo, incidiendo en los aspectos que, por circunstanciales y aparentemente no filosóficos, han sido tradicionalmente pasados por alto por los intérpretes.

7.

Los márgenes entre literatura y filosofía se difuminan en Platón, lo que debe hacernos comprender que esos márgenes son una necesidad interpretativa nuestra, que pertenecen a nuestros esquemas comprensivos. El fracaso de su aplicación debe llevarnos a reflexionar sobre su obviedad hermenéutica.

En efecto, no hay en la antigua Grecia un reparto de fronteras semejantè. En los diálogos de Platón, pero también en otros muchos lugares del corpus griego, la "poesía", por ejemplo, es situada dentro del núcleo de problemas quẹ conciernen a la sophía, esto es, dentro de un contexto de problemas relativos al saber y a la destreza. La Ilíada o la Odisea pueden entenderse como enciclopedias tribales, siempre y cuando no se escinda este carácter epistémico-pedagógico del especial cuidado lingüístico y demás aspectos ornamentales que rigen su composición ${ }^{19}$. La forma y el contenido de la literatura griega no son disociables, porque no hay aún una forma literaria que se considera neutra, como lo será la prosa en épocas posteriores. En Grecia, el metro y todo el cuidado lingüístico que acarrean sus formas poéticas son el horizonte de comprensión de la escritura, contra el que se recortan las excepciones, como la prosa de la historíe, ya sea la jónica o la de Heródoto, que se caracteriza, pues, por un marcado no-cuidado lingüístico ${ }^{20}$.

18 Cfr. PARDo ToRio, J. L, La regla del juego. La dificultad de aprender filosofia, Galaxia Gutemberg, Barcelona, 2004, pp. 279-291.

19 En este sentido, la denominación de enciclopedias tribales supone una abstracción interpretativa del contenido enunciativo epistémico que, por lo demás, se halla encabalgado en una también inescindible pragmática ritual que dista mucho de la neutralidad operacional técnica que presupone tal denominación. La praxis técnica y política que se describe en las epopeyas homéricas, por ejemplo, ha de encuadrarse dentro de su propio 
En cuanto a la philosophia, espero que se adivine ya que también el desdibujamiento de fronteras antes mencionado ha de hacernos repensar las categorizaciones que, acuñadas a. lo largo de distintas tradiciones con intereses y esquemas comprensivos totalmente ajenos al mundo griego, nos hacen leer a determinados autores como filósofos y a otros como literatos. Platón, en cuanto autor de una monumental obra narrativa que, sin embargo, consideramos ante todo patrimonio de la filosofía, puede ayudar, como ejemplo cristalino de ese desdibujamiento, a esa tarea de repensar una historia que es la de la griegos, pero que también es en cierto modo la nuestra.*

\section{Bibliografía}

Bobes Naves, M. C., Semiologia de la obra dramática, Taurus, Madrid, 1987.

Clay, D., Platonic questions. Dialogues with the Silent Philosopher, The Pennsylvania State UP, Pennsylvania, 2000. , “Plato's First Words", Yale Classical Studies 29, 1992, pp. 113-129.

Díaz LóPEZ, L., "El Fedro y su escena”, Kínesis, 09 (Edição Especial), 2013,pp. 87-98.

Esteban Santos, A., "Diálogo en la hierba: función de la introducción y del escenario del Fedro", en Aguilar, López Salvá, Rodríguez Alfageme (eds.), Charis didaskalias: homenaje a Luis Gil. Editorial Complutense, Madrid, 1994, pp. 291-304.

Gadamer, H.-G., Verdad y Método, Sígueme, Salamanca, 2005.

Garcia LANDA, J. A., Acción, relato, discurso. Estructura de la ficción literaria, Ediciones Universidad de Salamanca, Salamanca, 1998.

GonzÁlez, F. J. (ED.), The Third Way. New Directions in Platonic Studies, Rowman \& Littlefield, Maryland, 1995.

universo simbólico-conceptual, lo que debería llevarnos a una meditación sobre la para nosotros innegable, pero no por ello menos exenta de supuestos, neutralidad técnica. También el mundo secularizado de nuestra modernidad supone un conjunto de códigos y de esquemas comprensivos, aun cuando, por reacción a los códigos supersticiosos anteriores, haya podido ser entendido como lo carente de prejuicios. La objetividad científicotécnica es para nosotros lo neutro pero, en cuanto tal, tiene sus condiciones de producción y sus presupuestos, que distinguen un enunciado científico de uno que no lo es, y desde luego, un contexto politico-social en el que es preciso insertar su vocación de neutralidad.

20 Me remito aquí a los análisis de Felipe Martínez Marzoa en sus obras: El saber de la comedia, Antonio Machado Libros, Madrid, 2005, y El decir griego, Antonio Machado Libros, Madrid, 2006.

*Artículo recibido: 15 de noviembre de 2013. Aceptado: 6 de diciembre de 2013. 
Halliwell, S., "The Theory and the Practice of the Narrative in Plato" en Grethlein, RENGAKOS (EDS.), Narratology and Interpretation. The content of narrative form in ancient literature, Walter de Gruyter, Berlin-Nueva York, 2009, pp. 15-41.

HegeL, G. W. F., Lecciones sobre Historia de la Filosofia, FCE, México, 1981.

HeidegGer, M., Sein und Zeit, Max Niemeyer, Tubinga, 2006.

Johnson, W. A., "Dramatic frame and philosophic idea in Plato", The American Journal of Philology, 119:4, 1998, pp. 577-598.

LLEDÓ, E., El silencio de la escritura, Austral, Madrid, 1991. ,El surco del tiempo, Crítica, Barcelona 1992.

Lozano, J., Peña-Marín, C. \& Abril, G., Análisis del discurso, Cátedra, Madrid, 1982.

Martínez MarzoA, F., El decir griego, Antonio Machado Libros, Madrid, 2006.

2005 -, El saber de la comedia, Antonio Machado Libros, Madrid, 2005. , Ser y diálogo. Leer a Platón, Istmo, Madrid, 1996.

MorGan, K. A., "Plato", en De Jong, NüNLIST, BowIE (EDs.), Narrators, Narratees, and Narratives in Ancient Greek Literature: studies in Ancient Greek Narrative, Volumen One, Brill, Leiden-Boston, 2004, pp. 357-376.

PARDO TORIO, J. L, La regla del juego. La dificultad de aprender filosofia, Galaxia Gutemberg, Barcelona, 2004.

Press, G. A. (ED.), Plato's dialogues. New Studies and Interpretations, Rowman \& Littlefield, Maryland, 1993.

SpanG, K., Teoria del drama: lectura y análisis de una obra teatral, Eunsa, Pamplona, 1991. 